\title{
SKRINING PEMERIKSAAN TAJAM PENGLIHATAN (VISUS) PADA SISWA-SISWI KELAS V SEKOLAH DASAR DI LINGKUP KERJA PUSKESMAS MATIRODECENG, KABUPATEN PINRANG, SULAWESI SELATAN
}

\author{
Arlina Wiyata Gama \\ Program Studi Pendidikan Dokter \\ Fakultas Kedokteran dan Ilmu Kesehatan UIN Alauddin Makassar \\ arlinawiyatagama@gmail.com
}

\begin{abstract}
Abstrak
Penglihatan memerankan peranan penting dalam masa kanak-kanak, dan memiliki implikasi serius terhadap potensi belajar anak yang dapat membantu meningkatkan kualitas hidup. Secara Global, hampir 18,9 juta anak di bawah usia 15 tahun mengalami gangguan penglihatan. Tujuan penelitian ini adalah mengetahui gambaran prevelensi penurunan ketajaman penglihatan pada siswa-siswi Sekolah Dasar kelas 5 di wilayah kerja Puskesmas Matirodeceng Kabupaten Pinrang. Penelitian deskriptif dengan desain penelitian cross sectional dan teknik total sampling telah dilakukan pada bulan Oktober 2017 di 6 Sekolah Dasar yang berada di wilayah kerja Puskesmas Matirodeceng Kabupaten Pinrang. Hasil penelitian ini memperlihatkan bahwa pada siswa-siswi SD yang mengalami gangguan penurunan tajam penglihatan lebih banyak pada jenis kelamin laki-laki (22,7\%) dibandingkan jenis kelamin perempuan (12,8\%). Gangguan penurunan tajam penglihatan berdasarkan posisi mata didapatkan gangguan pada mata kiri $(13,9 \%)$ lebih banyak dibandingkan mata kanan $(11,1 \%)$. Nilai visus tertinggi dialami pada mata kanan siswa-siswi SD, seperti visus 20/200 dialami oleh 1 orang anak (0,7\%), visus 20/30 oleh 8 anak (5,6\%) pada mata kananya, sedangkan pada mata kiri 6 anak (4,2\%), dan visus 20/25 dialami oleh 3 anak $(2,1 \%)$ pada mata kanannya, sedangkan pada mata kiri 5 anak $(3,5 \%)$. Angka kejadian gangguan tajam penglihatan pada siswa-siswi Sekolah Dasar kelas 5 sebesar 17,4\%.
\end{abstract}

Kata Kunci : Skrining, Tajam Penglihatan, Anak Sekolah Dasar

\section{Pendahuluan}

Mata adalah panca indera yang paling penting dan memiliki fungsi yang sangat vital. Saat memasuki usia sekolah, penglihatan pada anak menjadi suatu hal yang sangat penting. ${ }^{1}$ Dengan penglihatan yang baik, proses belajar mengajar akan terjadi dengan baik, dimana salah satu jalur untuk menerima informasi dalam proses belajar adalah dengan penglihatan. Berbagai kelainan dapat terjadi pada mata, salah satunya adalah gangguan penurunan tajam penglihatan. Gangguan tajam penglihatan merupakan salah satu masalah kesehatan yang perlu diperhatikan dalam usia sekolah. Oleh karena itu pemeriksaan rutin untuk mendeteksi apakah terjadi gangguan tajam penglihatan sebaiknya dilakukan sedini mungkin. Hal ini bertujuan untuk mendeteksi (skrining) lebih awal gangguan tajam penglihatan yang akan mengganggu proses belajar siswasiswi Sekolah Dasar dalam menyerap materi dan juga akan berpotensi mengurangi kecerdasan apabila koreksi gangguan penglihatan terlambat dilakukan. Menurut WHO, diperkirakan hampir 18,9 juta anak di bawah 15 tahun mengalami gangguan tajam penglihatan. ${ }^{2,3}$

Tajam penglihatan merupakan kemampuan dalam melihat suatu objek. Pemeriksaan tajam penglihatan pada siswa-siswi 
Sekolah Dasar adalah bagian dari skiring awal yang harus disesuaikan dengan umur, kooperatif, kondisi neurologic dan kemampuan membaca, hal ini dikarenakan pada pemeriksaan tajam penglihatan menggunakan kartu Snellen. ${ }^{1,2}$

Indonesia adalah negara kepulauan tropis besar dengan populasi 195 juta dan Sulawesi Selatan memiliki 8 juta penduduk. Ada beberapa data dalam tingkat prevelance dan penyebab penurunan ketajaman visual di Indonesia. ${ }^{1,2}$ Sebagian besar kebutaan di Indonesia disebabkan oleh penyakit mata yang dapat diobati seperti kesalahan refraksi dan katarak. ${ }^{4}$ Tujuan penelitian ini adalah mengetahui gambaran prevelensi penurunan ketajaman penglihatan pada siswa-siswi Sekolah Dasar kelas 5 di wilayah kerja Puskesmas Matirodeceng Kabupaten Pinrang.

\section{Metode Penelitian}

Penelitian ini bersifat deskriptif dengan pendekatan cross sectional. Penelitian ini dilakukan di 6 Sekolah Dasar di wilayah kerja Puskesmas Matirodeceng Kabupaten Pinrang pada bulan Oktober 2017. Populasi penelitian ini adalah semua siswa-siswi kelas 5 Sekolah Dasar di wilayah kerja Puskesmas Matirodeceng Kabupaten Pinrang. Sampel penelitian ini menggunakan teknik total sampling yang memenuhi kriteria inklusi dan ekslusi.
Kriteria inklusi dalam penelitia ini adalah semua siswa-siswi kelas 5 Sekolah Dasar di wilayah kerja Puskesmas Matirodeceng Kabupaten Pinrang dan bersedia diperiksa selama penelitian. Sedangkan kriteria ekslusi dalam penelitian ini adalah siswasiswi kelas 5 Sekolah Dasar yang tidak datang selama pengumpulan data, mengalami penyakit mata yang dapat mempengaruhi penglihatan, seperti konjungtivitis, keratitis,dll. Data yang terhimpun akan diproses secara manual dan disajikan dalam bentuk tabel distribusi frekuensi yang dihitung dalam satuan persen dengan menggunakan analisis univariat pada setiap variabelnya.

\section{Hasil}

Hasil penelitian ini menunjukkan bahwa siswa-siswi kelas 5 Sekolah Dasar di wilayah kerja Puskesmas Matirodeceng Kabupaten Pinrang, 25 orang mengalami gangguan tajam penglihatan dan 119 orang tidak mengalami gangguan tajam penglihatan.

Karakteristik responden berdasarkan jenis kelamin (tabel 1) didapatkan bahwa 66 orang $(45,8 \%)$ laki-laki dan 78 orang $(54,2 \%)$ perempuan.

Berdasarkan tabel 1 didapatkan bahwa pada responden dengan jenis kelamin lakilaki lebih banyak yang mengalami gangguan tajam penglihatan yaitu sebesar 
$(22,7 \%)$, sedangkan pada responden dengan jenis kelamin perempuan $(12,8 \%)$,akan tetapi tidak terjadi perbedaan yang signifikan.

Tabel 2 menunjukkan bahwa sebanyak 17,4\% siswa-siswi Sekolah Dasar mengalami gangguan penglihatan dan penderita gangguan penurunan tajam penglihatan paling banyak ditemukan di SDN 88 (25,6\%), akan tetapi tidak ada perbedaan yang signifikan pada ke 5 Sekolah Dasar lainnya.

Tabel 3 didapatkan bawa skrining gangguan tajam penglihatan yang dilakukan pada 6 Sekolah Dasar yang berada di wilayah kerja puskesmas Matirodeceng dengan menggunakan Kartu Snellen menunjukkan sebanyak 20 orang $(13,9 \%)$ siswa-siswi Sekolah Dasar mengalami gangguan pada mata kiri, sedangkan sebanyak 16 orang $(11,1 \%)$ pada kiri. Dengan variasi nilai visus yang digambarkan pada tabel di bawah:

Tabel 4 menunjukkan bahwa gangguan tajam penglihatan dengan nilai visus yang tertinggi pada mata kanan dialami oleh 1 anak (0,7\%) dengan nilai visus 20/200 dan 8 anak (5,6\%) dengan visus 20/30. Pada mata kiri didapatkan nilai visus 20/30 dialami oleh 6 anak (4,2\%) dan visus 20/25 dialami 5 anak $(3,5 \%)$.

\section{Pembahasan}

Berdasarkan hasil penelitian di atas, gangguan penurunan ketajaman penglihatan pada siswa-siswi Sekolah Dasar tiap tahun akan terus meningkat jika tidak ditangani segera mungkin.

Dalam proses kegiatan belajar mengajar agar dapat menyerap dan memahami pelajaran, seorang siswa sangat ditunjang dengan adanya penglihatan yang baik, jika penglihatan terganggu, maka akan mempengaruhi proses tersebut. Adanya gangguan tajam penglihatan yang minimal, mungkin tidak akan disadari oleh siswa/siswi tersebut, hal ini terjadi karena kurangnya pemahaman siswa/siswi tentang proses gangguan penglihatan dan ketidakpekaan guru dalam memahami kondisi yang terjadi pada siswa tersebut. Banyak hal ang dapat terjadi jika gangguan penglihatan yang ringan dibiarkan, salah satunya akan menyebabkan kerusakan mata yang lebih parah dan prestasi belajar akan menurun.

Saw et all melakukan penelitian tentang penyebab low vision dan kebutaan di pedesaan Indonesia. Mereka studi menilai kesalahan bias yang tidak dikoreksi (penurunan ketajaman visual) adalah penyebab utama low vision unilateral dan bilateral di Sumatera, Indonesia, dan negara-negara Asia lainnya termasuk Cina, India, Hongkong dan Malaysia. ${ }^{2,3,4}$ Penelitian ini menyarankan untuk membuat program penyaringan masyarakat yang 
dapat dilaksanakan di daerah-daerah yang kurang terlayani di mana penyaringan penglihatan rutin dilakukan oleh petugas kesehatan dan masyarakat yang dididik tentang ketersediaan dan keterjangkauan koreksi untuk kesalahan bias. ${ }^{2,6}$

Darge $\mathrm{HF}$ et al mengulas sebuah studi tentang prevalensi gangguan ketajaman visual di antara anak-anak sekolah di Sekolah Dasar Arada Subcity di Addis Ababa, Ethiopia pada tahun 2017, mereka mencatat prevalensi gangguan penglihatan kurang dari penelitian yang dilakukan secara nasional di Ethiopia, ini rendah tingkat prevalensi mungkin karena perbedaan dalam desain penelitian dan daerah. Penelitian ini dilakukan pada siswa sekolah dasar di Addis Ababa, ibu kota Ethiopia, di mana layanan kesehatan mata tersedia dan kesadarannya baik. Studi ini merekomendasikan bahwa penyaringan sekolah diperlukan untuk deteksi dini dan kemungkinan manajemen. ${ }^{5,7}$

Yamamah dkk melakukan prevalensi gangguan penglihatan dan kesalahan bias pada anak-anak Sinai selatan, Mesir. Mereka meninjau studi berbasis populasi yang diterbitkan antara 2009 hingga 2010 untuk 2070 anak sekolah yang sehat di kota-kota Sinai Selatan dan permukiman Badui sekitarnya. Studi ini menemukan bahwa total $29,4 \%$ anak-anak Sinai selatan memiliki beberapa bentuk gangguan penglihatan, 90,32\% di antaranya terdiri dari kesalahan bias (penurunan ketajaman visual) yang secara signifikan dikoreksi dengan kacamata. ${ }^{8,9,10}$

Lian-Hong Pi et al melakukan penelitian yang menyelidiki prevalensi kesalahan bias, gangguan penglihatan dan penyakit mata pada anak-anak usia sekolah di Cina barat. Studi ini menemukan bahwa di antara anak-anak usia sekolah di daerah yang kurang dari Cina barat, kesalahan bias adalah kelainan mata yang paling umum, dan kesalahan bias yang tidak dikoreksi adalah penyebab utama gangguan penglihatan. $^{4}$

Vishnuprasad dkk melakukan penelitian pada 1884 anak-anak sekolah yang tergabung dalam kelompok usia 10-14 tahun di Puducherry, India. Studi ini menemukan bahwa prevalensi gangguan penglihatan bahkan lebih tinggi di antara anak-anak yang termasuk sekolah wilayah perkotaan atau sekolah swasta. Anak-anak dengan riwayat keluarga positif menggunakan tontonan lebih cenderung memiliki gangguan penglihatan. Prevalensi gangguan penglihatan meningkat seiring dengan bertambahnya usia anak. ${ }^{11}$

\section{Kesimpulan}

Berdasarkan hasil dan pembahasan di atas, Angka kejadian gangguan tajam penglihatan pada siswa-siswi Sekolah Dasar kelas 5 sebesar 17,4\%, akan tetapi 
penurunan tajam penglihatan pada siswasiswi ini masih tergolong gangguan visus yang ringan.

Saran yang bisa diberikan kepada pihak sekolah adalah dengan menerapkan kebijakan kesehatan sekolah tentang skrining pemeriksaan tajam penglihatan sebelum penerimaan siswa-siswi di Sekolah Dasar dan program skrining mata tahunan untuk mendeteksi dini serta melakukan penanganan sesegera mungkin jika ada gangguan tajam penglihatan pada siswa-siswi Sekolah Dasar.

\section{DAFTAR PUSTAKA}

1. World Health Organization: Blindness and Vision Impairment. Retrieved December 5,2018, form hhtps://www.who.int/newsroom/fact-sheets/detail/blindness-andvisual-impairment.html

2. Awan AR, Jamshed J, Khan MM, Latif Z. Prevalence and causes of visual impairment and blindness among school children in Muzaffarabad, Pakistan. Int J Sci Rep 2018;4(4):93-8

3. Vidya R, Kiran KG. Prevalence of Ocular Morbidities of Children in Higher Primary Schools in Rural Areas of Mangalore. Int J Community Med Public Health. 2017;4(8):2859-63

4. Pi LH, Chen L, Liu Q, Ke N, Fang J, Zhang $\mathrm{S}$, et al. Prevalence of Eye Diseases and Causes of Visual Impairment in School-
Aged Children in Western China. J Epidemiol. 2012;22(1):37-44

5. Gilbert C, Foster A. Childhood blindness in the context of VISION 2020-the right to sight. Bull World Health Organ. 2001;79:227-32

6. S.M. Saw, R. Husaun, G. M. Gazzard, D. Koh, D. Widjaja, and D. T. Tan. Causes of Low vision and blindness in rural Indonesia. The british journal of ophthalmology, vol.87,pp.2075-1078, 2003

7. Zainal M, Ismail SM, Ropilah AR, et al. Prevalence of blindness and low vision in Malaysian population: result from the National Eye Survey. Br J Ophthalmol 2002;86:951-6

8. Saw SM,Gazzad G, Koh D, et al. Prevalence rates of refractive errors in Sumatra, Indonesia. Invest Ophthalmol Vis Sci 2002;43:3174-80

9. Darge HF, Shibru G, Mulugenta A, Dagnachew YM. The Prevalence of Visual Acuity Impairment among School Children at Arada Subcity Primary Schools in Addis Ababa, Ethiopia. J Ophthalmol 2017;9326108:1-7

10. Yamamah GAN, Alim AATA, Mostafa YS, Ahmed RAAS, Mahmoud AM. Prevalence of Visual Impairment and Refractive Errors in Children of South Sinai, Egypt. J Ophthalmic Epidemiol. 2015;22(4):246-54

11. Vishnuprasad R, Bazroy J, Madhanraj K, Prashanth HR, Singh Z, Samuel AK, et al. Visual impairment among 10-14 year school children in Puducherry: A cross sectional study. J Family Med Primary Care. 2017;6:5862 
Tabel 1. Distribusi Hasil Berdasarkan Jenis Kelamin Siswa-Siswi Sekolah Dasar Di Wilayah Kerja Puskesmas Matorideceng.

\begin{tabular}{ccccccc}
\hline \multirow{2}{*}{ Jenis Kelamin } & \multicolumn{7}{c}{ Pemeriksaan Tajam Penglihatan (visus) } & \multirow{2}{*}{ Jumlah } & \multirow{2}{*}{ \% } \\
& Sakit & \% & Tdk Sakit & \% & & \\
\hline Laki-laki & 15 & 22,7 & 51 & 77,3 & 66 & 45,8 \\
Perempuan & 10 & 12,8 & 68 & 87,2 & 78 & 54,2 \\
Total & 25 & 17,4 & 119 & 82,6 & 144 & 100 \\
\hline
\end{tabular}

Tabel 2. Distribusi Hasil Berdasarkan Tempat Sekolah Dasar

Di Wilayah Kerja Puskesmas Matirodeceng

\begin{tabular}{|c|c|c|c|c|c|c|}
\hline \multirow{2}{*}{ Lokasi } & \multicolumn{4}{|c|}{ Pemeriksaan Tajam Penglihatan (visus) } & \multirow{2}{*}{ Jumlah } & \multirow{2}{*}{$\%$} \\
\hline & Sakit & $\%$ & Tdk Sakit & $\%$ & & \\
\hline SDN 88 & 11 & 25,6 & 32 & 74,4 & 43 & 29,9 \\
\hline SDN 89 & 3 & 13,6 & 19 & 86,4 & 22 & 15,3 \\
\hline SDN 173 & 2 & 8,3 & 22 & 91,7 & 24 & 16,7 \\
\hline SDN 252 & 4 & 18,2 & 18 & 81,8 & 22 & 15,3 \\
\hline SDN 253 & 4 & 22,2 & 14 & 77,8 & 18 & 12,5 \\
\hline SDN 254 & 1 & 6,7 & 14 & 93,3 & 15 & 10,4 \\
\hline Total & 25 & 17,4 & 119 & 82,6 & 144 & 100 \\
\hline
\end{tabular}

Tabel 3. Distribusi Hasil Berdasarkan Posisi Mata Mata Siswa-Siswi Sekolah Dasar Di Wilayah Kerja Puskesmas Matirodeceng

\begin{tabular}{ccccccc}
\hline \multirow{2}{*}{ Posisi Mata } & \multicolumn{2}{c}{ Hasil Pemeriksaan Tajam Penglihatan $($ visus $)$} & \multirow{2}{*}{ Jumlah } & \multirow{2}{*}{$\%$} \\
\hline Mata Kanan & Sakit & \% & Tdk Sakit & \% & & 100 \\
Mata Kiri & 20 & 11,1 & 128 & 88,9 & 144 & 100 \\
\hline
\end{tabular}

Tabel 4. Distribusi Hasil Berdasarkan Nilai Visus Mata Siswa-Siswi Sekolah Dasar Di Wilayah Kerja Puskesmas Matirodeceng

\begin{tabular}{lcccc}
\hline \multicolumn{1}{c}{ Nilai Visus } & Mata Kanan & $\begin{array}{c}\text { Pemeriksaan Tajam Penglihatan (visus) } \\
\text { \% }\end{array}$ & Mata Kiri & \% \\
\hline $\mathbf{2 0} / \mathbf{2 0 0}$ & 1 & 0,7 & 0 & 0 \\
$\mathbf{2 0 / 1 0 0}$ & 2 & 1,4 & 2 & 1,4 \\
$\mathbf{2 0} / \mathbf{7 0}$ & 1 & 0,7 & 0 & 0 \\
$\mathbf{2 0 / 5 0}$ & 0 & 0 & 4 & 2,8 \\
$\mathbf{2 0} / \mathbf{4 0}$ & 1 & 0,7 & 3 & 2,1 \\
$\mathbf{2 0 / 3 0}$ & 8 & 5,6 & 6 & 4,2 \\
$\mathbf{2 0 / 2 5}$ & 3 & 2,1 & 5 & 3,5 \\
$\mathbf{2 0} / \mathbf{2 0}$ (Normal) & 128 & 88,9 & 124 & 86,1 \\
Total & 144 & 100 & 144 & 100 \\
\hline
\end{tabular}

